\title{
Tolerance of Isolated Rabbit Hearts to Short Ischemic Periods Is Affected by Increased LV Mass Fraction
}

\author{
M. HLAVÁČOVÁ ${ }^{*}$, V. OLEJNÍČKOVÁ ${ }^{2} *$ M. RONZHINA ${ }^{3}$, T. STRAČINA ${ }^{2}$, \\ O. JANOUŠEK ${ }^{3}$, M. NOVÁKOVÁ ${ }^{2,4}$, P. BABULA ${ }^{2,4}$, J. KOLÁŘOVÁ ${ }^{3}$, I. PROVAZNÍK ${ }^{3}$, \\ H. PAULOVÁ ${ }^{1}$ \\ * These authors contributed equally to this work.
}

${ }^{1}$ Department of Biochemistry, Faculty of Medicine, Masaryk University, Brno, Czech Republic, ${ }^{2}$ Department of Physiology, Faculty of Medicine, Masaryk University, Brno, Czech Republic, ${ }^{3}$ Department of Biomedical Engineering, Faculty of Electrical Engineering and Communication, University of Technology, Brno, Czech Republic, ${ }^{4}$ International Clinical Research Centre, St. Anne's University Hospital, Brno, Czech Republic

Received February 26, 2016

Accepted February 2, 2017

On-line April 12, 2017

\begin{abstract}
Summary
Hypertrophied hearts are known for increased risk of arrhythmias and are linked with reduced ischemic tolerance. However, still little is known about state characterized only by increased left ventricle (LV) mass fraction. Seventeen isolated rabbit hearts with various LV mass were divided into two groups according to LV weight/heart weight ratio (LVW/HW ratio), namely group $\mathrm{H}$ and $\mathrm{L}$ (with higher and lower LVW/HW ratio, respectively) and underwent three short cycles of global ischemia and reperfusion. The differences in electrogram (heart rate, $\mathrm{QRS}_{\max }$, mean number, onset and dominant form of ventricular premature beats) and in biochemical markers of myocardial injury (creatine kinase, lactate dehydrogenase - LDH) and lipid peroxidation (4-hydroxy-2-nonenal - 4-HNE) were studied. As compared to group $\mathrm{L}$, hearts in group $\mathrm{H}$ exhibited lower tolerance to ischemia expressed as higher incidence and severity of arrhythmias in the first ischemic period as well as increase of LDH and 4-HNE after the first reperfusion. In the third cycle of ischemia-reperfusion, the preconditioning effect was observed in both electrophysiological parameters and LDH release in group $\mathrm{H}$. Our results showed consistent trends when comparing changes in electrograms and biochemical markers. Moreover, 4-HNE seems to be good potential parameter of moderate membrane alteration following ischemia-reperfusion injury.
\end{abstract}

\section{Key words}

Rabbit isolated heart $\bullet$ LV mass $\bullet$ Global ischemia • Electrogram • 4-hydroxy-2-nonenal

\section{Corresponding author}

H. Paulová, Department of Biochemistry, Faculty of Medicine, Masaryk University, Kamenice 753/5, bld. A16, 62500 Brno, Czech Republic. E-mail: hpaulova@med.muni.cz

\section{Introduction}

Since the coronary artery disease still represents one of the major causes of morbidity and mortality in many countries, ischemia-reperfusion injury is worth of further research. Using various models, it has been intensely studied from many aspects, largely employing biochemical and electrophysiological methods.

Myocardial ischemia-reperfusion injury is a complex pathophysiological process. Ischemic period is characterized mainly by decreased ATP level leading to ion imbalance and cell acidosis. In cardiomyocytes, the impairment of the membrane transport mechanisms due to lack of ATP results in a decrease of resting transmembrane potential, action potential (AP) amplitude and duration and eventually in altered conduction velocity (Elharrar and Zipes 1977, Shaw and Rudy 1997). The resulting tissue 
inhomogeneity may lead to arrhythmias, frequently by re-entry mechanism (Elharrar and Zipes 1977). In reperfusion, the reintroduction of molecular oxygen to the ischemic region leads to excessive generation of reactive oxygen species (ROS), the central mediators of reperfusion injury originating from mitochondria (Raedschelders et al. 2012). Superoxide radical $\left(\mathrm{O}_{2}{ }^{-}\right)$is considered the parent radical from which other radicals originate. The hydroxyl radical $(\cdot \mathrm{OH})$ is particularly harmful because cells do not have antioxidant enzymes for its removal. $\cdot \mathrm{OH}$ attacks all sorts of macromolecules. If polyunsaturated fatty acids in membrane lipids are targeted, formation of secondary peroxidation products such as malondialdehyd, acrolein or 4-hydroxy-2-nonenal (4-HNE) follows. 4-HNE is known for its high reactivity and cytotoxic potential (Poli et al. 2008) and also its participation in development of hypertrophy was described (Calamaras et al. 2012). On the other hand, positive effect of ROS is also known (Kalogeris et al. 2014). In ischemic preconditioning, several cycles of ischemia and reperfusion provoke certain changes in signaling pathways leading to protection of the heart. Preconditioned hearts show lower incidence of arrhythmias and reduced infarct size (Halestrap et al. 2007).

A specific situation is observed if a mass of the left ventricle significantly increases. Bigger mass of myocardium requires higher oxygen and nutrient supply and may therefore potentiate tissue vulnerability to ischemia. Moreover, higher number of mitochondria may produce even more ROS and damage during reperfusion may escalate (Muntean et al. 2016). In patients suffering from hypertrophic cardiomyopathy, significantly decreased tolerance to ischemia and intensification of ischemic heart symptoms was previously reported (Efthimiadis et al. 2014).

In ischemia-reperfusion studies, numerous models including isolated heart are used due to possibility to analyze multiple parameters in detail without modulation by neurohumoral inputs (Olejníčková et al. 2015). From experimentally used species, rabbit is appropriate model because of electrophysiological similarity of its heart with human myocardium (Kaese et al. 2013). Predisposition of rabbit heart to spontaneous myocardial hypertrophy was previously reported (Chitty 2015). Therefore, the aim of this study was to assess tolerance of isolated rabbit hearts to repeated ischemic insults with respect to various left ventricle mass fraction. Also biochemical parameters which describe moderate alteration of myocardial membranes related to ischemic insult were studied.

\section{Materials and Methods}

All experiments were carried out with respect to recommendations of the European Community Guide for the Care and Use of Laboratory Animals. The experimental protocol was approved by Local Committee for Animal Treatment at Masaryk University, Faculty of Medicine.

\section{Isolated heart preparation}

Seventeen adult New Zealand rabbits (both sexes, weight $2.2-3.45 \mathrm{~kg}$ ) were included to the study. The animals were purchased from certified supplier (Velaz, Czech Republic). Animals were premedicated by diazepam (Apaurin, Krka, Slovenia, $2 \mathrm{mg}$ i.m.) and anesthetized by mixture of xylazin (Narkamon, Spofa, Czech Republic, $2 \mathrm{mg} / \mathrm{kg}$ i.m.) and ketamine (Calypsol, Gedeon Richter, Hungary, $60 \mathrm{mg} / \mathrm{kg}$, i.m.). Heparin (Heparin Léčiva, Zentiva, Czech Republic, 1000 IU/kg) was administered intravenously to avoid blood clotting. To avoid ischemia during preparation the animals were artificially ventilated (ventilator for small laboratory animals, World Precision Instruments, USA). Bilateral thoracotomy was performed and the hearts were excised and placed into cold Krebs-Henseleit solution $\left(4^{\circ} \mathrm{C}\right)$. The aorta was cannulated, the hearts were fixed to a modified Langendorff apparatus (Olejníčková et al. 2015) and perfused at constant pressure $(70 \mathrm{~mm} \mathrm{Hg})$ with KrebsHenseleit solution $\left(\mathrm{NaCl}, 118.1 \mathrm{mM}\right.$; $\mathrm{NaHCO}_{3}, 27.1 \mathrm{mM}$; $\mathrm{KCl}, 4.8 \mathrm{mM} ; \mathrm{KH}_{2} \mathrm{PO}_{4}, 1.0 \mathrm{mM} ; \mathrm{MgSO}_{4}, 1.2 \mathrm{mM}$; $\mathrm{CaCl}_{2}, 1.2 \mathrm{mM}$; glucose, $10.1 \mathrm{mM}$ ) continuously aerated by pneumoxyd $\left(95 \% \mathrm{O}_{2}\right.$ and $\left.5 \% \mathrm{CO}_{2}\right)$. The temperature was maintained at $37^{\circ} \mathrm{C}$. The hearts were stabilized during first $30 \mathrm{~min}$ of perfusion. The experimental protocol consisted of 3 repeated ischemia-reperfusion series: 10 minutes-lasting global ischemia induced by stopping of perfusion was followed by 10 minutes-lasting reperfusion (Fig. 1). The flow of coronary effluent was measured as an overflow from the bath in which the heart was placed.

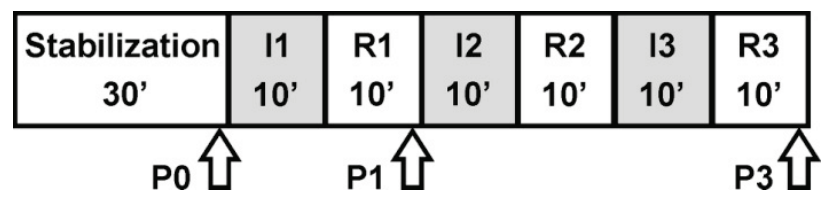

Fig. 1. Design of experimental protocol. I - ischemia, $\mathrm{R}$ - reperfusion, $\mathrm{P}$ 0, 1, 3-collection of coronary effluent samples at stabilization, the first and the third reperfusion, respectively. 


\section{Electrogram recording and analysis}

During the whole experiment, three electrograms (EGs) were recorded simultaneously by touchless method using the orthogonal lead system (Kolárová et al. 2010). The signals were amplified by a set of three biological amplifiers DAM50 (World Precision Instruments, USA) and further simultaneously digitized by 16-bit $\mathrm{AD}$ converters at a sampling rate of $2000 \mathrm{~Hz}$ using a data acquisition multifunction card PCI-6250 (National Instruments, USA). Analysis of electrogram included heart rate, QRS complex parameters and ventricular arrhythmias assessment. The heart rate (HR) was calculated in each $5^{\text {th }}$ minute of experiment and normalized to the end of stabilization period (100\%). QRS complexes in EG recorded from middle area of LV were delineated. Duration and maximal deflection of QRS (QRSd and QRSmax, respectively) were then calculated to evaluate possible effect of LV mass changes on ventricular electrical activity. The ventricular arrhythmias were classified into singles, salvos and ventricular tachycardia (VT) according to the Lambeth conventions (Curtis et al. 2013). The total number of ventricular premature beats (VPBs) in each minute of the experiment was assessed manually.

\section{Biochemical analysis}

The samples of coronary effluent were collected at the end of stabilization period and at the end of the first and the third reperfusion (P0, P1, and P3 in Fig. 1, respectively). Levels of two cardiac enzymes (creatine kinase - CK, lactate dehydrogenase - LDH) were measured immediately using commercial kits (ErbaLachema, Czech Republic) according to the manufacturer's instructions. The results were expressed in nkat. $\min ^{-1}$.

All chemicals used in biochemical analyses of 4-hydroxy-2-nonenal (4-HNE) were of the p.a. or HPLC grade, purchased from Sigma-Aldrich (St. Louis, MO, USA). The standard of 4-HNE was obtained from Cayman Chemical (Ann Arbor, MI, USA). Determination of 4-HNE was performed according to Kinter (1996) with slight modification as described previously (Hlaváčová et al. 2015). Briefly, the 4-HNE concentration in coronary effluent was measured by HPLC with UV detection after derivatization by 2,4-dinitrophenylhydrazine and subsequently calculated according to the standard curve and expressed in nmol.min ${ }^{-1}$.

\section{Histological evaluation}

Immediately after the end of isolated heart experiment, sample of tissue from the LV lateral wall was collected, embedded in freezing medium and frozen into liquid nitrogen. Samples were then stored at $-20{ }^{\circ} \mathrm{C}$ until further processing. Sections of $10 \mu \mathrm{m}$ thickness were cut by cryostat, dehydrated and stained. For general morphology, hematoxylin and eosin staining was used. Masson's trichrome staining was used to assess and visualize the extent of fibrosis in myocardium. Microscope Nikon Eclipse Ti-S/L100 (Nikon, Japan) and NIS elements software (Nikon, Japan) was used to process images and to evaluate the resultant pictures.

\section{Distribution of the animals into groups}

The body weight (BW) of animals was assessed before experiment followed by preparation of the heart. At the end of experiment, various anatomical characteristics of hearts were measured: heart weight (HW), left ventricle weight (LVW) and left ventricle wall thickness (LVT). Different visual characteristics were noticed during preparation and course of experiment. Retrospectively, for more detailed analysis of heart morphology following indexes were calculated: the heart weight to body weight $(\mathrm{HW} / \mathrm{BW})$ ratio, the $\mathrm{LV}$ weight to body weight (LVW/BW) ratio and LV weight to heart weight $(\mathrm{LVW} / \mathrm{HW})$ ratio. Based on the abovementioned results animals were distributed into two groups according to the value of $\mathrm{LVW} / \mathrm{HW}$ ratio which represents the LV fraction in the whole heart mass and was the only index suitable for dividing the animals. To calculate the discrimination threshold value, commonly used receiver operating characteristic analysis (Fawcett 2006) was performed. As a result, the threshold ratio was set to 0.57 so the animals with ratio below or equal 0.57 belong to group $\mathrm{L}(\mathrm{N}=8,2$ females and 6 males) and above 0.57 belong to group $\mathrm{H}(\mathrm{N}=9,2$ females and 7 males).

\section{Statistical analysis}

The statistical analyses were performed using GraphPad Prism ${ }^{\circledR} 5$ (version 5.01, GraphPad Software, Inc., San Diego, CA, USA) and Matlab R2014b (The MathWorks, Inc., USA). Normality of data distribution was verified using Shapiro-Wilk test. Non-parametric Mann-Whitney U test was used to test the differences between $\mathrm{L}$ and $\mathrm{H}$ groups in following data sets: 1) basic characteristics (body weight, heart weight and others), 2) QRS complex parameters $\left(\mathrm{QRS}_{\mathrm{d}}\right.$ and 
$\mathrm{QRS}_{\max }$ ) in stabilization period, 3) number of VPBs in each ischemic period, 4) values of biochemical parameters calculated at the end of stabilization, the first and the third reperfusion periods (Fig. 1). Additionally, the differences in values of biochemical parameters between various periods of experiment were verified using non-parametric Friedman repeated measurement test followed by multiple comparison Tukey-Kramer test. Correlation analysis (Spearman's rank correlation coefficient $\rho$ calculated for $\mathrm{L}$ and $\mathrm{H}$ group separately) was performed to examine the relationship between values of different biochemical parameters in particular experimental period and also between values of each parameter calculated in different periods. The values of heart rate were expressed as mean \pm SEM. Differences in the HR between L and $\mathrm{H}$ groups were analyzed by parametric Student's unpaired t-test. The differences between consecutive experimental periods were analyzed by paired t-test. Differences between individual periods of each experiment and its stabilization period were analyzed by one-sample t-test. For all tests, $p<0.05$ was considered significant.

\section{Results}

\section{Basic characteristics of data sets}

No significant differences in anatomical parameters were found between $\mathrm{L}$ and $\mathrm{H}$ group. LVW/HW ratio was the only parameter in which these groups differed significantly $(p=0.002$, Mann-Whitney U test). Spearman's $\rho$ between all pairs of basic characteristics were also calculated. Significant correlation $(\mathrm{p}<0.05)$ was confirmed between body weight and heart weight ( $\rho=0.86$ in $\mathrm{H}$ group), heart weight and left ventricle weight $(\rho=0.97$ and $\rho=0.84$ in $L$ and $\mathrm{H}$ group, respectively).

\section{Electrophysiological assessment of ischemic tolerance}

As expected, HR was affected by ischemic insult. In $\mathrm{H}$ and $\mathrm{L}$ group, HR decreased in ischemic periods and was almost restored during the reperfusion periods. In group L, the decrease was significant in all ischemic periods with better recovery after the first ischemia when compared with group $H$. On the other hand, the HR decrease in group $\mathrm{H}$ was lower in all ischemic periods with better recovery in the second and the third reperfusion periods. Almost all HR changes were significant when comparing two consecutive periods of experiment in both groups. However, no significant changes between the $\mathrm{L}$ and $\mathrm{H}$ groups were found when comparing the same period of experiment (Fig. 2).

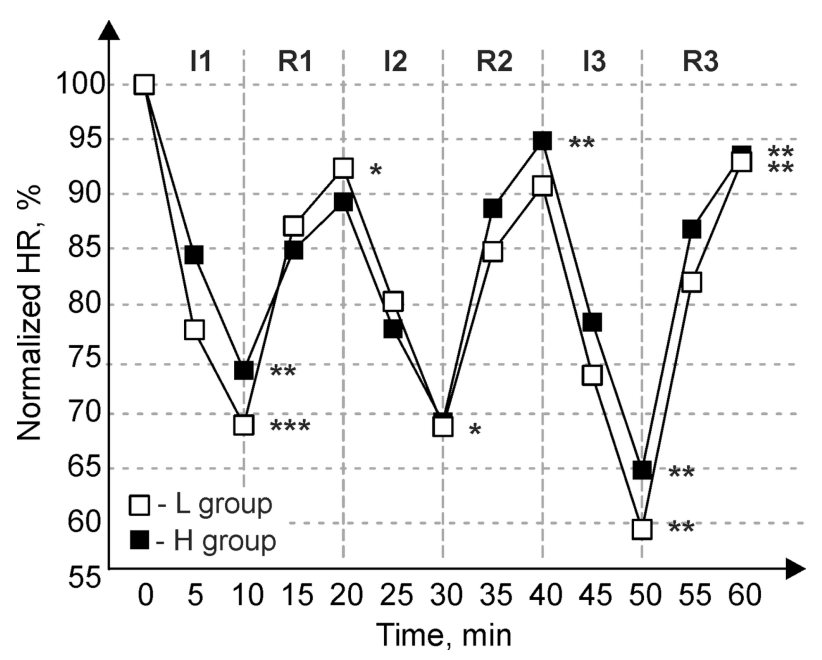

Fig. 2. Mean values of normalized $H R$ for $L$ and $H$ group. $H R$ values significantly different from those in previous experimental phase are depicted with $*, * *$ and $* * *$ for $\mathrm{p}<0.05$, $\mathrm{p}<0.001$ and $\mathrm{p}<0.0008$, respectively. I - ischemia, $\mathrm{R}$ - reperfusion.

The change in LV anatomy was reflected in value of $\mathrm{QRS}_{\max }$ only. $\mathrm{QRS}_{\max }$ calculated in $\mathrm{H}$ group reached significantly higher value $(p<0.05)$ than that in L group (mean \pm SEM): $2.54 \pm 1.37 \mathrm{mV}$ and $4.46 \pm 1.52 \mathrm{mV}$ in $\mathrm{L}$ and $\mathrm{H}$ group, respectively.

Last, arrhythmias were evaluated to assess tolerance of hearts to ischemia-reperfusion injury. During the first ischemia, the mean number of VPBs was higher in group $H(32.9 \pm 17.9$ vs. $14.5 \pm 11.0$ in L, respectively). The difference has been found in the onset of VPBs (the $6^{\text {th }}$ minute vs. the $5^{\text {th }}$ minute in $\mathrm{H}$ and $\mathrm{L}$, respectively). Salvos dominated in $\mathrm{H}$ and singles in L group. During the second ischemia, decrease of the mean number of VPBs was observed in both groups (to $96 \%$ and $15 \%$ in $\mathrm{H}$ and $\mathrm{L}$, respectively). The onset of arrhythmias was delayed (to the $7^{\text {th }}$ minute in both groups). Although the dominant form of arrhythmias during the second ischemia remained unchanged in both groups, there was a worsening in the severity of arrhythmias during the third ischemia (VT in group $\mathrm{H}$ and salvos in group L, respectively). In group $\mathrm{H}$, the decrease of total VPBs and also delay of onset of arrhythmias continued (to $14 \%$ and the $9^{\text {th }}$ minute). In group L, the onset of arrhythmias remained the same (the $7^{\text {th }}$ minute), however the total VPBs slightly increased (Table 1 and Fig. 3). None arrhythmias were observed in any reperfusion period in both groups. 
Table 1. Mean number of different types of VPBs in group $L$ and $H$.

\begin{tabular}{llcccc}
\hline Period & Group & Singles & Salvos & VT & Total \\
\hline \multirow{4}{*}{$I 1$} & $L$ & $11.1 \pm 11.1$ & $3.1 \pm 2.6$ & $0.3 \pm 0.3$ & $14.5 \pm 11.0$ \\
& $H$ & $6.8 \pm 3.7$ & $22.2 \pm 14.3$ & $3.9 \pm 3.3$ & $32.9 \pm 17.9$ \\
$I 2$ & $L$ & $2.2 \pm 1.5$ & 0 & 0 & $2.2 \pm 1.5$ \\
& $H$ & $3.3 \pm 2.3$ & $23.8 \pm 14.8$ & $4.7 \pm 0.9$ & $31.8 \pm 18.1$ \\
$I 3$ & $L$ & $2.6 \pm 2.4$ & $4.2 \pm 3.8$ & 0 & $6.8 \pm 5.9$ \\
& $H$ & $0.2 \pm 0.2$ & $1.0 \pm 1.0$ & $3.3 \pm 3.3$ & $4.5 \pm 3.4$ \\
\hline
\end{tabular}

Values are means \pm SEM. I1, I2, I3 - ischemia, VT - ventricular tachycardia.

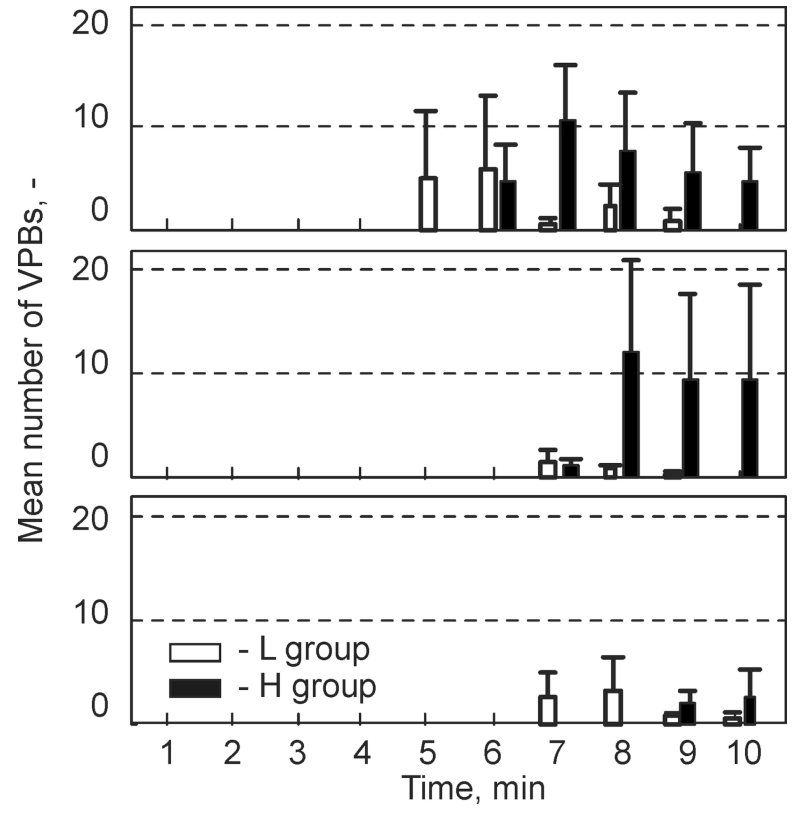

Fig. 3. Distribution of VPBs in each minute over the first, the second and the third ischemia (top, middle and bottom panel, respectively) in group $\mathrm{L}$ and $\mathrm{H}$.

\section{Biochemical assessment of ischemic tolerance}

The values of biochemical parameters (CK, $\mathrm{LDH}$ and 4-HNE) related to flow of coronary effluent are shown in Figure 4. There was no significant difference between group $\mathrm{L}$ and $\mathrm{H}$ in any determined parameter and phase of experiment. Nevertheless in group $\mathrm{H}$ slightly increasing trend in the level of LDH and 4-HNE after the first ischemic period was found. The trend was more visible in values of 4-HNE, where the difference between stabilization period and the first reperfusion was close to significant $(\mathrm{p}=0.055)$. But in the third reperfusion period the trend in levels of LDH and 4-HNE was not the same: while the level of LDH started to decrease slightly, values of 4-HNE showed continuing increase. The increasing trend of 4-HNE and LDH after the first ischemia was not visible in group L. On the contrary, values of biochemical parameters in the first reperfusion were the same (LDH) or even lower (4-HNE) with slight increase of both parameters in the third reperfusion period. The values of $\mathrm{CK}$ do not show any trend in any group due to wide dispersion of values. a)

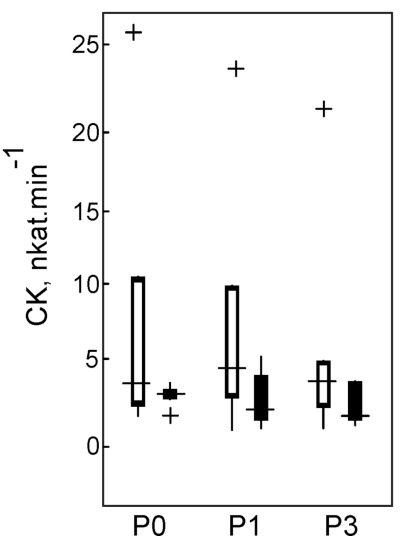

b)

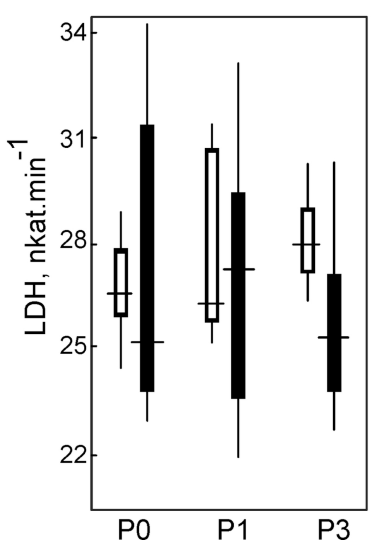

c)

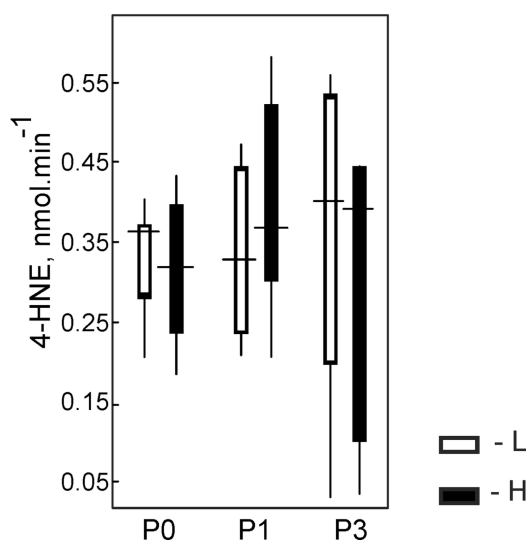

Fig. 4. Values of biochemical parameters $\mathrm{CK}(\mathbf{a}), \mathrm{LDH}(\mathbf{b})$ and 4-HNE (c) for $\mathrm{L}$ and $\mathrm{H}$ group in different periods of experiment. Displayed as median, the edges of the box indicate $25^{\text {th }}-75^{\text {th }}$ percentiles. P0, P1 and P3 - samples of coronary effluent at the end of stabilization, the first and the third reperfusion, respectively. 
Table 2. Correlations between the values of different biochemical parameters within experimental period and correlations between the values of biochemical parameter from various experimental periods in group $\mathrm{H}$.

\begin{tabular}{llcl}
$\begin{array}{l}\text { Biochemical } \\
\text { parameter }\end{array}$ & Period & Spearman's $\rho$ & p-value \\
\hline LDH vs. 4-HNE & $P 0$ & 0.862 & $0.009^{*}$ \\
& $P 1$ & 0.700 & $0.043^{*}$ \\
& $P 3$ & 0.261 & 0.594 \\
4-HNE & $P 0$ vs. P1 & 0.850 & $0.012^{*}$ \\
& $P 1$ vs. P3 & 0.841 & $0.044^{*}$ \\
& $P 0$ vs. P3 & 0.638 & 0.200 \\
\hline
\end{tabular}

P0, P1, P3 - samples of coronary effluent taken in the end of stabilization period, the first and the third reperfusion. ${ }^{*} \mathrm{p}<0.05$.

Correlation analysis was performed among values of studied biochemical parameters in particular experimental periods between group $\mathrm{L}$ and $\mathrm{H}$ and no correlations were found. We also examined the relationship between values of each parameter calculated in different periods in the same group. The correlations were calculated separately for group $\mathrm{H}$ and L. Relevant correlations were found only in group $H$. Positive correlation between values of 4-HNE and LDH in samples P0 and P1 were observed. Moreover, from all followed biochemical parameters, only values of 4-HNE positively correlate among all experimental periods (Table 2).

\section{Histological evaluation}

Histological analysis revealed that the cardiomyocytes from $\mathrm{H}$ vs. L group did not differ as the short axis dimension is concerned. Representative pictures of midventricular sections stained with Masson's trichrome are shown in Figure 5a. In the content of collagen apparent although insignificant difference between group $\mathrm{H}$ and $\mathrm{L}$ was found ( $\%$ blue $1.09 \pm 0.69 \%$ vs. $0.62 \pm 0.25 \%$, for group $\mathrm{H}$ and L, respectively, Fig. 5b). a

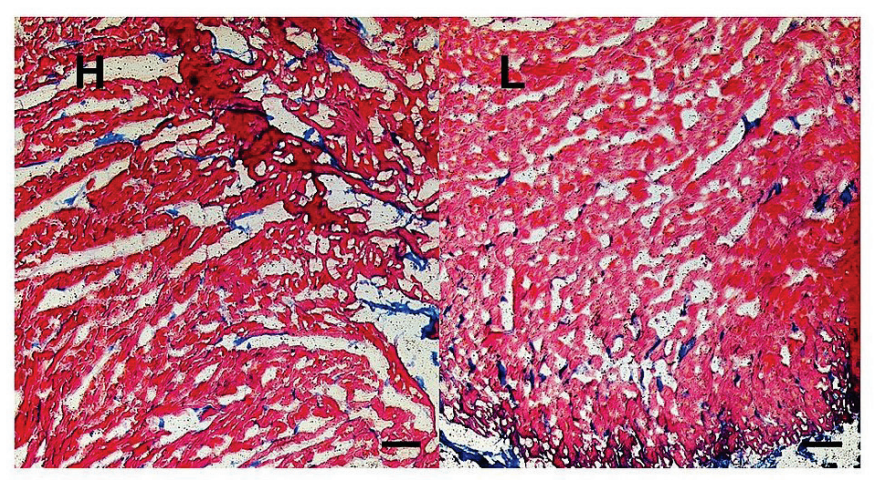

b

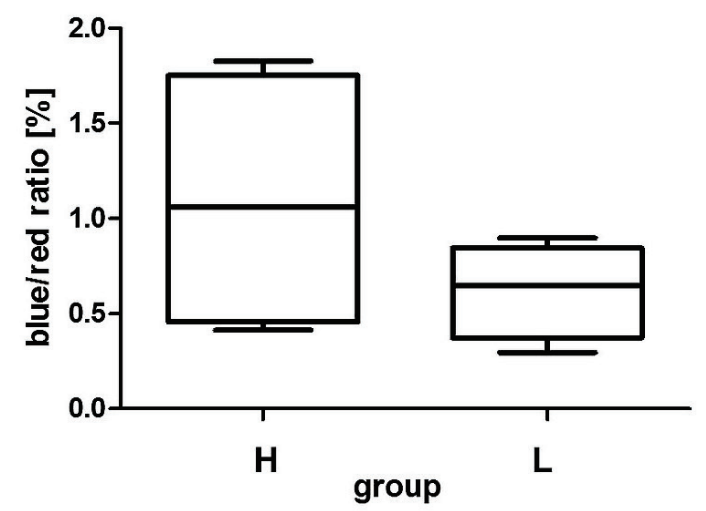

Fig. 5. Histological analysis of heart tissue. a) Representative pictures of midventricular section of the left ventricle in group $H(H$, left) and group $L(L$, right). Collagen is stained blue (Masson's trichrome staining). A bar represents $100 \mu \mathrm{m}$. b) Ratio of collagen (stained blue) to non-collagen tissue (stained red) in the Masson trichrome staining (in \%). Displayed as median, the edges of the box indicate $25^{\text {th }}-75^{\text {th }}$ percentiles.

\section{Discussion}

Cardiovascular diseases are still a leading cause of morbidity and mortality. It is well known that pathologically hypertrophic hearts are at high risk of arrhythmias and sudden cardiac death and may develop into heart failure (Verdecchia et al. 2001, Lorell et al. 2000). Besides other consequences hypertrophy is characterized by increased oxidative stress via production of ROS, which are involved both in the progress of cardiac hypertrophy and also alter directly the function of ion channels (Giordano 2005). Therefore, cardiac hypertrophy is widely studied in experimental and clinical medicine. However, it is still little known about state which precedes manifested hypertrophy. The aim of this study was to find whether even slight increase of $\mathrm{LV}$ mass expressed as $\mathrm{LVW} / \mathrm{HW}$ ratio may change myocardial tolerance to ischemia. Biochemical markers suitable for detection of moderate alteration of membranes during ischemia-reperfusion injury were searched for.

In this work we first focused on characterization 
of hearts with slight increase of LV mass, which might be therefore at higher risk of later progress in hypertrophy. After more detailed statistical analysis the animals were divided according to LVW/HW ratio into group L (lower values of ratio) and $\mathrm{H}$ (higher values of ratio). The assessment of LV enlargement in humans is generally based on calculation of LVW using LV volume parameters estimated noninvasively by echocardiographic or magnetic resonance techniques. Because of large differences in body size of subjects and its close relation to LVW, various formulas have been proposed for LVW normalization by parameters representing the body size, such as body weight (BW), body surface area or body mass index (Foppa et al. 2005). Wolk et al. (2001) reported a rabbit model of induced hypertrophy where the increase of LVW/BW ratio in group with induced hypertrophy was about $25 \%$ comparing to control group. In the present study, in group $\mathrm{H}$ (animals with spontaneously increased LV mass fraction) the increase is only $4 \%$. So it is evident that elevation of this parameter is not as significant as in hypertrophied hearts. It is in agreement with the results of statistical analysis, in which the LVW/HW ratio is the only index affected by increase of the LV mass fraction. Our distribution to the group with higher (group H) and lower (group L) LV mass fraction is also supported by a trend toward increased content of collagen in myocardium and significant increase of maximal amplitude of QRS under non-ischemic condition. Correlation between quantity of collagen and sudden cardiac death in patients with LV hypertrophy was shown in study of Tamarappoo et al. (2012). Increased QRS $S_{\max }$ reflects increased LV mass; the Framingham study reported that only the increased voltage of QRS complex is independent risk of cardiovascular mortality (Kannel 1970). These findings support the distribution according to the left ventricle weight to heart weight ratio, which more sensitively demarks hearts with bigger left ventricle mass and changes connected with this condition.

After distribution of animals into group $\mathrm{L}$ and $\mathrm{H}$ the tolerance of hearts in both groups to ischemiareperfusion injury was examined. In group $\mathrm{H}$, hearts were more susceptible to ischemic insults expressed both by higher mean number of arrhythmias and their higher severity in both the first and the second ischemic period. Different redox signaling in the hearts with increased LV mass (Sag et al. 2014) may explain their higher susceptibility to ischemia and reperfusion. This is consistent with other studies, where the relation between left ventricular hypertrophy and higher incidence of arrhythmias was manifested (Chatterjee et al. 2014). In the third ischemic period, reduced total VPBs number and the delayed onset was observed in group $\mathrm{H}$. This effect may result from ischemic preconditioning. It is supported by better recovery of HR after the second ischemia and lower decrease of heart rate in the third ischemic period in this group.

For biochemical analyses, three parameters were chosen. Creatine kinase and lactate dehydrogenase (LDH) are rough parameters of direct myocardial injury and cell necrosis. The third parameter - 4-hydroxynonenal (4-HNE) - is a marker of lipid peroxidation which occurs mainly in reperfusion (Eaton et al. 1999). From abovementioned parameters, only the values of LDH and 4-HNE showed some differences. In group $\mathrm{H}$, the increase of LDH and 4-HNE after the first reperfusion, in case of 4-HNE nearly significant, confirms higher susceptibility of these hearts to the ischemic insult comparing with group L. This finding is supported by study of Blasig et al. (1995) where significantly higher release of 4-HNE in group of hypertrophic hearts compared with control group after global ischemia was proven. It is also known that cardiac hypertrophy is characterized by increased glucose uptake with reduction in phosphocreatine/ATP ratio described even in patients without developed hypertrophy (Crilley et al. 2003). It is possible that this situation of bioenergetic deficit is a stimulus, which causes higher susceptibility of hearts in group $\mathrm{H}$ to another energetically complicated condition, which ischemia undoubtedly is. In the third reperfusion, the level of LDH restores more or less to the stabilization level, but the amount of 4-HNE keeps slight increase and shows wider variability as demonstrated in correlation analysis. It might indicate that preconditioning affected LDH release, while moderate and fast non-enzymatic changes of lipoperoxidation on membrane continue with further ischemic periods despite the preconditioning. Such a rough parameter as LDH does not reflect these changes. In addition, there are some associations among electrophysiological and biochemical changes, as described in our previous work discussing correlations between ischemic-induced arrhythmias and production of hydroxyl radicals, which are known precursors of lipid peroxidation (Paulová et al. 2013). For comparison, the animals were divided according to their body weight as a rough anatomical parameter (below and above $3 \mathrm{~kg}$ ). Results revealed that the differences in electrophysiological as well as biochemical results were 
minimized and less homogenous than when groups $\mathrm{H}$ and L were compared, even when the animals differed significantly not only in body weight but also in LV weight, which is used in assessment of LV enlargement.

In summary, certain trends in incidence and severity of arrhythmias and values of biochemical markers were found between the groups with lower and higher left ventricle mass expressed by LVW/HW ratio, which attenuate after dividing the animals into groups according to body weight. Hearts with higher LV mass fraction showed lower tolerance to ischemic insult. From biochemical markers studied, 4-hydroxynonenal is a promising marker of moderate membrane alteration following ischemia-reperfusion injury. Outcomes of this study may be beneficial for future research in the field of the first pathological steps of developing myocardial hypertrophy.

\section{Conflict of Interest}

There is no conflict of interest.

\section{Acknowledgements}

This publication was written at Masaryk University as part of the project "Př́spěvek chemických a biochemických metodik ke studiu molekulární podstaty vybraných patologických stavů a onemocnění" no. MUNI/A/1056/2015 and "Kardiovaskulární systém očima molekulární fyziologie“" no. MUNI/A/1355/2016 with the support of the Specific University Research Grant, as provided by the Ministry of Education, Youth and Sports of the Czech Republic in the year 2016. This work was also supported by the grant projects of the Grant agency GAČR P102/12/2034 and by the project no. LQ1605 from the National Program of Sustainability II (MEYS CR).

\section{References}

BLASIG IE, GRUNE T, SCHÖNHEIT K, ROHDE E, JAKSTADT M, HASELOFF RF, SIEMS WG: 4-Hydroxynonenal, a novel indicator of lipid peroxidation for reperfusion injury of the myocardium. Am J Physiol Heart Circ Physiol 269: H14-H22, 1995.

CALAMARAS TD, LEE C, SIWIK DA, COLUCCI WS: The lipid peroxidation product 4-hydroxy-2-nonenal (HNE) causes cardiac myocyte hypertrophy and activates hypertrophic MAP kinase signaling. Free Radic Biol Med 53: S156, 2012.

CHATTERJEE S, BAVISHI C, SARDAR P, AGARWAL V, KRISHNAMOORTHY P, GRODZICKI T, MESSERLI FH: Meta-analysis of left ventricular hypertrophy and sustained arrhythmias. Am J Cardiol 117: 1049-1052, 2014.

CHITTY J: Cardiovascular disease in rabbits. Companion Anim 20: 74-78, 2015.

CRILLEY JG, BOEHM EA, BLAIR E, RAJAGOPALAN B, BLAMIRE AM, STYLES P, MCKENNA WJ, ÖSTMAN-SMITH I, CLARKE K, WATKINS H: Hypertrophic cardiomyopathy due to sarcomeric gene mutations is characterized by impaired energy metabolism irrespective of the degree of hypertrophy. J Am Coll Cardiol 41: 1776-1782, 2003.

CURTIS MJ, HANCOX JC, FARKAS A, WAINWRIGHT CL, STABLES CL, SAINT DA, CLEMENS-JEWERY H, LAMBIASE PD, BILLMAN GE, JANSE MJ, PUGSLEY MK, NG GA, RODEN DM, CAMM AJ, WALKER MJA: The Lambeth conventions (II): guidelines for the study of animal and human ventricular and supraventricular arrhythmias. Pharmacol Ther 139: 213-248, 2013.

EATON P, LI JM, HEARSE DJ, SHATTOCK MJ: Formation of 4-hydroxy-2-nonenal modified proteins in ischemic rat heart. Am J Physiol Heart Circ Physiol 276: H935-H943, 1999.

EFTHIMIADIS GK, PAGOURELIAS ED, GOSSIOS T, ZEGKOS T: Hypertrophic cardiomyopathy in 2013: current speculations and future prospectives. World J Cardiol 6: 26-37, 2014.

ELHARRAR V, ZIPES DP: Cardiac electrophysiologic alterations during myocardial ischemia. Am J Physiol Heart Circ Physiol 2: H329-H345, 1977.

FAWCETT T: An introduction in FOC analysis. Pattern Recogn Lett 27: 861-874, 2006.

FOPPA M, DUNCAN BB, ROHDE LEP: Echocardiography-based left ventricular mass estimation. How should we define hypertrophy? Cardiovasc Ultrasound 3: 1-13, 2005.

GIORDANO FJ: Oxygen, oxidative stress, hypoxia and heart failure. J Clin Invest 115: 500-508, 2005. 
HALESTRAP AP, CLARKE SJ, KHALIULIN I: The role of mitochondria in protection of the heart by preconditioning. Biochim Biophys Acta 1767: 1007-1031, 2007.

HLAVÁČOVÁ M, GUMULEC J, STRAČINA T, FOJTU゚ M, RAUDENSKÁ M, MASAŘíK M, NOVÁKOVÁ M, PAULOVÁ H: Different doxorubicin formulations affect plasma 4-hydroxy-2-nonenal and expression of aldehyde dehydrogenase 3A1 and thioredoxin reductase 2 in rat. Physiol Res 64 (Suppl 5): S653-S660, 2015.

KAESE S, FROMMEYER G, VERHEULE S, VAN LOON G, GEHRMANN J, BREITHARDT G, ECKARDT L: The ECG in cardiovascular-relevant animal models of electrophysiology. Herzschrittmacherther Elektrophysiol 24: 84-91, 2013.

KALOGERIS T, BAO Y, KORTHUIS RJ: Mitochondrial reactive oxygen species: a double edged sword in ischemia/reperfusion vs preconditioning. Redox Biol 2: 702-714, 2014.

KANNEL WB, GORDON T, CASTELLI WP, MARGOLIS JR: Electrocardiographic left ventricular hypertrophy and risk of coronary heart disease. The Framingham study. Ann Intern Med 72: 813-822, 1970.

KINTER M: Quantitative analysis of 4-hydroxy-2-nonenal. In: Free Radicals: A Practical Approach. NA PUNCHARD, GJ KELLY (eds), Oxford University Press, Oxford, 1996, pp 133-145.

KOLÁŘOVÁ J, FIALOVÁ K, JANOUŠEK O, NOVÁKOVÁ M, PROVAZNÍK I: Experimental methods for simultaneous measurement of action potentials and electrograms in isolated heart. Physiol Res 59 (Suppl 1): S71-S80, 2010.

LORELL BH, CARABELLO BA: Left ventricular hypertrophy - pathogenesis, detection, and prognosis. Circulation 102: 470-479, 2000.

MUNTEAN DM, STURZA A, DĂNILĂ MD, BORZA C, DUICU OM, MORNOŞ C: The role of mitochondrial reactive oxygen species in cardiovascular injury and protective strategies. Oxid Med Cell Longev 2016: 8254942, 2016.

OLEJNÍČKOVÁ V, NOVÁKOVÁ M, PROVAZNÍK I: Isolated heart models: cardiovascular system studies and technological advances. Med Biol Eng Comput 53: 669-678, 2015.

PAULOVÁ H, STRAČINA T, JARKOVSKÝ J, NOVÁKOVÁ M, TÁBORSKÁ E: Hydroxyl radicals' production and ECG parameters during ischemia and reperfusion in rat, guinea pig and rabbit isolated heart. Gen Physiol Biophys 32: 221-228, 2013.

POLI G, SCHAUR R, SIEMS W, LEONARDUZZI G: 4-hydroxynonenal: a membrane lipid oxidation product of medicinal interest. Med Res Rev 28: 569-631, 2008.

RAEDSCHELDERS K, ANSLEY DM, CHEN DDY: The cellular and molecular origin of reactive oxygen species generation during myocardial ischemia and reperfusion. Pharmacol Ther 133: 230-255, 2012.

SAG CM, SANTOS CXC, SHAH AM: Redox regulation of cardiac hypertrophy. $J$ Mol Cell Cardiol 73: 103-111, 2014.

SHAW RM, RUDY Y: Electrophysiologic effects of acute myocardial ischemia: a theoretical study of altered cell excitability and action potential duration. Cardiovasc Res 35: 256-272, 1997.

TAMARAPPOO BK, JOHN BT, REINIER K, TEODORESCU C, UY-EVANADO A, GUNSON K, JUI J, CHUGH SS: Vulnerable myocardial interstitium in patients with isolated left ventricular hypertrophy and sudden cardiac death: a postmortem histological evaluation. J Am Heart Assoc 1: e001511, 2012.

VERDECCHIA P, CARINI G, CIRCO A, DOVELLINI E, GIOVANNINI E, LOMBARDO M, SOLINAS P, GORINI M, MAGGIONI AP: Left ventricular mass and cardiovascular morbidity in essential hypertension: the MAVI study. J Am Coll Cardiol 38: 1829-1835, 2001.

WOLK R, SNEDDON KP, DEMPSTER J, KANE KA, COBBE SM, HICKS MN: Regional electrophysiological effects of left ventricular hypertrophy in isolated rabbit hearts under normal and ischaemic conditions. Cardiovasc Res 48: 120-128, 2000. 